\title{
Scrotal reconstruction by inguinal flap after Fournier's gangrene: A case report and review of literature
}

\author{
Marvin Richie Dongmo Tsopmene, David Ngaroua, \\ Joseph Eloundou Ngah, Ignagali Ousmaila Bianpambe
}

\begin{abstract}
Introduction: Fournier's gangrene is a necrotizing fasciitis of the perineo-scrotal region. It is a medical and surgical emergency justifying a prompt multidisciplinary management. Improvement of the functional and aesthetic outcome is still a big challenge for the medical community. Case Report: This is a case of a Fournier's gangrene in a 25-yearold man, having as risk factors 10 years alcohol consumption and a bad personal hygiene. About $70 \%$ of the scrotal skin surface was lost to the debridement. A pedicle inguinal flap was used for scrotal reconstruction, following conventional iterative dressing, with satisfactory esthetic and functional results three months later. Conclusion: Rapid diagnosis followed by a radical debridement is the mainstay of management of Fournier's gangrene. Pedicle inguinal flap is a technique of choice for reconstruction of major scrotal skin defects in resource limited settings.
\end{abstract}

Keywords: Fournier's gangrene, Inguinal flap, Scrotal reconstruction

Marvin Richie Dongmo Tsopmene ${ }^{1}$, David Ngaroua ${ }^{2}$, Joseph Eloundou $\mathrm{Ngah}^{3}$, Ignagali Ousmaila Bianpambe ${ }^{1}$

Affiliations: ${ }^{1}$ Medical Doctor, General practitioner, Faculty of Medicine and Biomedical Sciences of the University of Yaounde, St Marie of Salapoumbe Catholic Hospital; ${ }^{2}$ Medical Doctor, General Surgeon, Faculty of medicine of Garoua; ${ }^{3}$ Professor of Medicine, Neurosurgeon, Faculty of Medicine and biomedical sciences of the university of Yaounde.

Corresponding Author: Tsopmene Dongmo Marvin Richie, MD, Medical Doctor, General practitionerSalapoumbé Hospital, Cameroon; Email: pyt.tsopmene@gmail.com

Received: 09 April 2018

Accepted: 16 May 2018

Published: 04 June 2018

\section{How to cite this article}

Tsopmene MRD, Ngaroua D, Ngah JE, Bianpambe IO. Scrotal reconstruction by inguinal flap after Fournier's gangrene: A case report and review of literature. Int J Case Rep Images 2018;9:100920Zo1MT2018.

Article ID: 100920Zo1MT2018

$* * * * * * * * *$

doi: 10.5348/100920Zo1MT2018CR

\section{INTRODUCTION}

Fournier's gangrene is a rapidly extensive necrotizing fasciitis of the perineum and external genitalia, resulting in extensive soft tissue necrosis. First description made in the 10th century by Avicenne, it was then formalized by Jean Alfred Fournier in 1883. The diagnosis is made on clinical grounds.Contrary to Fournier's specification of male youth in scrotal gangrene, there is an increasing sex and age mix of patients suffering from the disease. The basic pathological process, necrotizing fasciitis, has been identified in the perineum of women and children, although the disease afflicts the male more often than the female [1]. It is mainly of colorectal (16-45\%) and genitourinary $(20-43 \%)$ origin [2]. It is a medical and surgical emergency that requires early multidisciplinary management. Despite a growing understanding of the pathogenesis of Fournier's gangrene and advances in intensive medical treatment, this disease, which usually has a fulminant course, and due to septic complications and multi-organ failure, still carries a high mortality rate ranging from $20 \%$ to $80 \%$ according to the literature [3]. Early assessment and an aggressive targeted management of FG are crucial for a better outcome [4]. Fournier's gangrene poses a real aesthetic and functional problem, which must be solved by an adequate reconstruction surgery technique. 


\section{EDORIUM Journals}

Int J Case Rep Images 2018;9:100920Z01MT2018.

www.ijcasereportsandimages.com

\section{CASE REPORT}

A 25-year-old man, alcoholic for 10 years, living in a rural area among the Baka pygmies of eastern Cameroon, with poor personal hygiene, has been complaining of painful scrotal swelling from five days. On clinical examination, he was in good general state, and had scrotal necrosis sparing the perineum. Surgical debridement, performed after urinary diversion with an indwelling transurethral catheter, showed tissue necrosis of approximately $70 \%$ of the scrotal tissue. The left testicle was partially covered by the remaining scrotal skin while the right one was completely exposed. Stabilization of the lesions was obtained after 96 hours of iterative debridement. A wet classic dressing was placed and changed every 48 hours. We had a good local evolution under wet dressing. Five weeks later, scrotal reconstruction was done with a right pedicle inguinal flap (Figure 1), Figure 2(A and B). The steps of the surgical technique were:

- Mark de skin reflection of the inguinal ligament by drawing a line from the pubic tubercle to the anterior superior iliac spine

- The superficial circumflex iliac artery is located on the midline dividing the inguinal ligament, $2.5 \mathrm{~cm}$ distal to the inguinal ligament

- The superficial circumflex iliac artery runs even to the inguinal ligament, directed to the lateral aspect of the thigh

- We delineated the flap margins. The central axis of the inguinal flap was that of the superficial circumflex iliac artery. The flap maximal length was $19 \mathrm{~cm}$, while width was $10 \mathrm{~cm}$

- Skin incision began on the superior edge of the flap

- Dissection is done underneath inferior epigastric vessels

- Dissection is followed to the lateral edge of Sartorius muscle without any incision on its aponeurosis

- The flap was then lifted carefully and positioned for grafting.

The urinary catheter was removed two weeks later. The patient returned home 10 weeks after admission and four weeks after scrotal reconstruction. Clinical examination three months following scrotal reconstruction revealed a satisfactory aesthetic and functional result (Figure 3). The sensitivity of neo- scrotum and testes were normal. Erection, ejaculation and urination were normal.

\section{DISCUSSION}

Mentioned for the first time in the 1oth century by Avicenne in his "canon de la médecine", Fournier's gangrene was described by Baurienne in 1764 and Hebler in 1848 and formalized by Jean Alfred Fournier in 1883. Fournier's gangrene is a necrotizing fasciitis

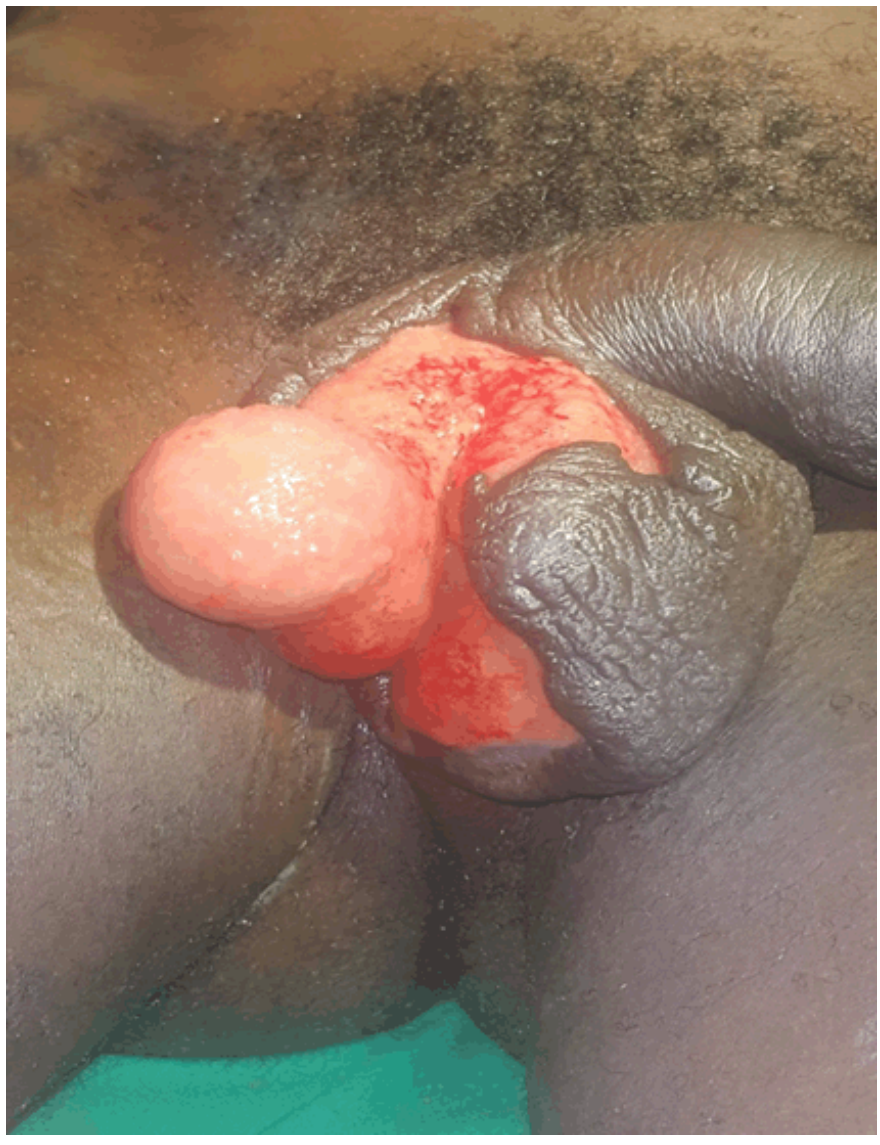

Figure 1: Skin defect after four weeks of conventional dressing.

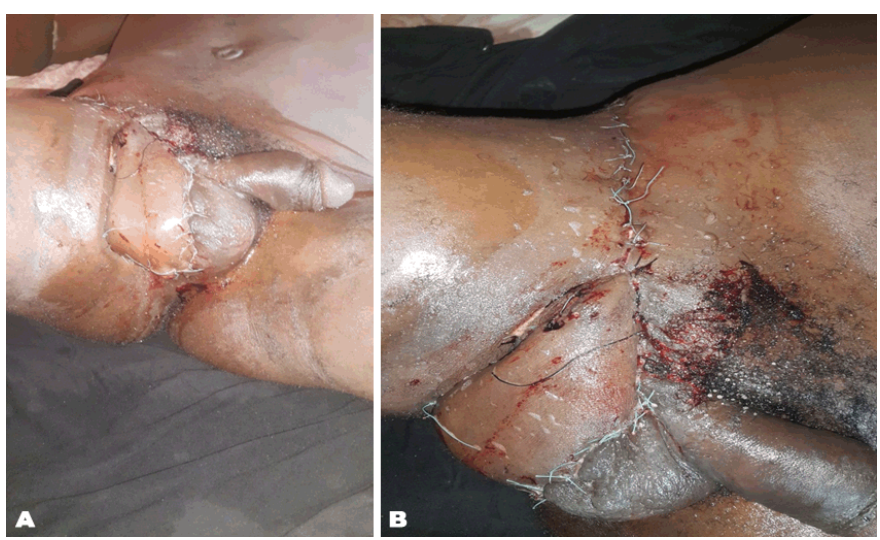

Figure 2(A and B): Postoperative aspect of the scrotal region after reconstruction by a pedicle inguinal flap.

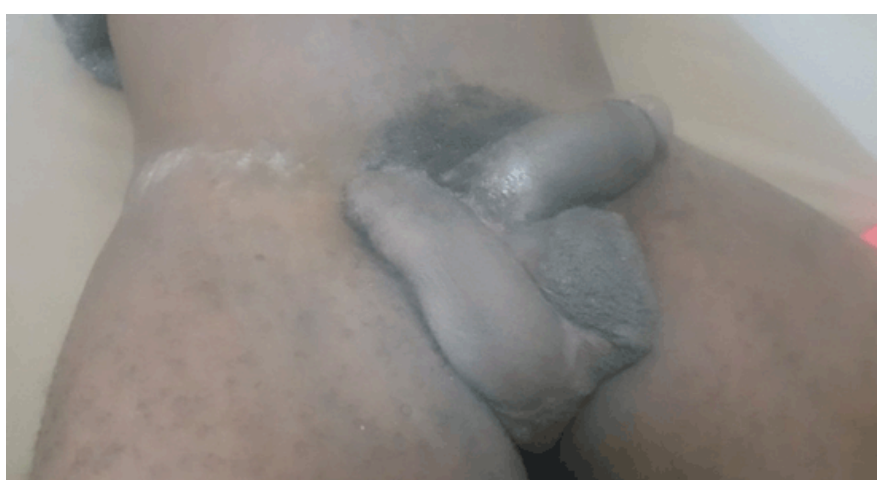

Figure 3: Postoperative aspect of the scrotal region tree months after reconstruction by a pedicle inguinal flap. 


\section{EDORiUM Journals}

primarily affecting the perineum and the scrotal region, rapidly extensive along contiguous fasciae. The infection spreads along Colle's fascia, Buck's fascia, and the dartos according to the point of origin. It results in an inflammatory response leading to obliterative endarteritis with cutaneous and subcutaneous vascular thrombosis with corollary necrosis of soft tissues. The incidence is lower in men than in women. In the literature, the lower incidence of Fournier's gangrene in women is hypothetically explained by anatomical structures, which allow better drainage of secretions in the female pelvis [5]. Fournier's gangrene is secondary in 81.8-95.5\%, mainly perirectal (16-45\%) and genitourinary (20-43\%) $[1-3,5]$. Fournier's gangrene is a polymicrobial infection in $82.5 \%$ of cases and affects mainly men, with a sex ratio of $10 / 1[6,7]$. In women, the distribution of causes is more even with a focus on the external and internal genitalia. The literature suggests that Fournier's gangrene in women may arise from vulvar or Bartholin's gland abscesses or may result from episiotomy or hysterectomy [8]. Unlike the first descriptions of the disease made by Jean Alfred Fournier and according to recent studies, Fournier's gangrene mainly affects men with comorbidities, from their fifth decade $[6,7,9]$. The risk factors associated with Fournier gangrene are: Diabetes, chronic alcoholism, immunosuppression, obesity, prolonged immobilization, poor personal hygiene, urethral stricture and malnutrition [2, 6, 10]. According to Czymek et al, the average consultation delay is six days ( 2 to 28 days) while Dje et al reported in their series $64 \%$ of patients with a consultation delay longer than seven days $[6,11]$. The clinical diagnosis of Fournier's gangrene is usually obvious. However, the help of complementary explorations is two-fold. On one hand, they allow positive diagnosis, especially in the early stages of the disease, making it possible to initiate an early treatment. On the other hand, they measure the systemic repercussions of the disease whose knowledge is useful for medical treatment and prognosis. Multidisciplinary treatment must be initiated without delay. The prognosis depends greatly on rapid implementation of therapeutic measures. Korkul et al reported higher mortality in the group of patients with a management delay greater than 7 days compared to the group with a management delay of less than 7 days, which was statistically significant [12]. These results are similar to those of Dje et al, who reported high mortality in the group of patients with a management delay greater than 7 days compared to those with a management delay of less than 7 days, a difference which, however, was not statistically significant [11]. Studies suggest that female patients with Fournier's gangrene have a significantly higher mortality rate, which is associated with a significantly higher incidence of peritonitis and retroperitonitis [13]. For this reason, Czymeke et al assumed that once the inflammatory cascade of bacterial synergism with vascular thrombosis and subsequent necrosis is activated, better drainage of secretions in the female pelvis becomes a fatal disadvanwhich allows the inflammatory process to spread more rapidly to the trunk and eventually leads to multi-organ failure [8]. Medical treatment includes resuscitation measures to correct cardiovascular hemodynamic disorders, electrolyte disorders, renal failure and respiratory failure as well as nutritional disorders. It is followed by a massive, probabilistic, intravenous, triple antibiotic therapy, of broad spectrum of action, targeting the most frequently encountered germs, started after bacteriological sampling and adapted as soon as possible [2, 9]. Finally, tetanus serotherapy, and heparin therapy according to coagulation studies. Surgical treatment has three phases; the initial debridement, followed by the healing phase and finally the reconstructive plastic surgery [2]. Debridement, performed under general anesthesia, begins with aggressive removal of necrotic tissues until macroscopically healthy tissue is seen $[6,11]$. Two to six repeated debridement is generally necessary [2]. In our case, we had to perform four debridement sessions. To avoid retraction of the spermatic cords and alteration of the testes, the testicles can be placed in subcutaneous pouches in the thigh [2]. We did not carry out this procedure because according to the results of a systematic review published by Karian et al, this method exposes to a risk of infertility linked to a high temperature of the testes during their sojourn in those cutaneous pouches [14]. It is noted in the literature that in combination with debridement, a left colostomy is performed in $60 \%$ to $100 \%$ of cases, in order to avoid contamination of wounds by feces [2]. We did not perform a colostomy because there was no perineal involvement. In addition, according to Ozturk et al, colostomy is primarily necessary for wellselected patients, particularly in cases where gangrene is of perirectal starting point. They also noted that the stoma did not seem to influence the evolution of the disease and resulted in a significant extra cost [15]. Urinary diversion must be systematic [2]. The healing phase is done by iterative dressings, which could be wet classic dressings for several weeks, natural untransformed honey, a vacuum aspiration closure system (VAC) or hyperbaric oxygen therapy. Without VAC nor hyperbaric oxygen therapy box, we used conventional iterative dressing. Many authors recently reported a better clinical and aesthetic outcome following the use of honey compared to conventional dressing [2]. Plastic surgery for scrotal and perineal defect reconstruction is often necessary and depends on the delay of reconstruction, the size of the skin defect, the local skin capital and the general state of the patient [3]. Reconstruction of skin defect can be through healing by second intention, delayed primary closure, local scrotal advancement flap, split-thickness skin graft or flaps, which could be fasciocutaneous or musculocutaneous. Karian et al recently proposed in a systematic review, an algorithm for the reconstruction of skin defects in Fournier's gangrene [14]. They recommend local scrotal advancement flaps, with or without incorporation of the dartos muscle, for patients with defects confined to less than $50 \%$ of the scrotum that 


\section{EDORIUM Journals}

cannot be closed primarily without tension. For defects larger than $50 \%$ of the scrotum or extending beyond the scrotum, they recommend split-thickness skin grafting or flap reconstruction. We used a pedicle inguinal flap for scrotal reconstruction. This type of reconstruction technique described by Cannistra et al, is simple and do not require localization of the circumflex superficial iliac artery [10]. Inguinal flap is easy to perform, allows coverage of the scrotal area with a relatively thick, sensitive tissue, with moderate scar tissue formation [10].

\section{CONCLUSION}

Fournier's gangrene is a major medical and surgical emergency. Prompt diagnosis associated with aggressive debridement is the mainstay of management. The goal of reconstructive surgery is both functional and aesthetic. The choice for surgical reconstruction depends on the reconstruction time, the size of the skin defect, the local skin capital and the general state of the patient. Pedicle inguinal flap is a reconstruction technique of choice in resource-limited settings to cover major skin defects. The prognosis depends on the delay of management, the presence or not of diabetes.

\section{REFERENCES}

1. Lipsker A, Leroux F, Saint G, Pignot G. Gangrène de Fournier: Prise en charge chirurgicale. [Article in French]. Prog Urol 2014;24(2):80-5.

2. Eke N. Fournier's gangrene: A review of 1726 cases. $\mathrm{Br}$ J Surg 2000 Jun;87(6):718-28.

3. Chabak H, Rafik A, Ezzoubi M, Diouri M, Bahechar N, Chlihi A. Reconstruction of scrotal and perineal defects in Fournier's gangrene. Modern Plast Surg 2015;5(33):23-7.

4. Oliviera C, Vale L, Pereira P, et al. Fournier's gangrene: An overview of predictive factors of mortality in a large contemporary series. Eur Urol Suppl 2018;17(2):e1318.

5. Ferreira PC, Reis JC, Amarante JM, Fournier's gangrene: A review of 43 reconstructive cases. Plast Reconstr Surg 2007 Jan;119(1):175-84.

6. Czymek R, Hildebrand P, Kleemann M, et al. New insights into the epidemiology and etiology of Fournier's gangrene: A review of 33 patients. Infection 2009 Aug;37(4):306-12.

7. Czymek R, Kujath P, Bruch HP, et al. Treatment, outcome and quality of life after Fournier's gangrene: A multicentre study. Colorectal Dis 2013 Dec;15(12):1529-36.

8. Czymek R, Frank P, Limmer S, et al. Fournier's gangrene: Is the female gender a risk factor? Langenbecks Arch Surg 2010 Feb;395(2):173-80.

9. Hubert J, Fournier G, Mangin P, Punga-Maole M. Gangrene of the external genitalia. [Article in French]. Prog Urol 1995 Dec;5(6):911-24.

10. Cannistra C, Kirsch-Noir F, Delmas V, Marmuse JP, Boccon-Gibod L. Scrotal reconstruction by inguinal flap after Fournier's gangrene. [Article in French]. Prog Urol 2003 Sep;13(4):703-6.

11. Dje K, Lebeau R, Diane B, Vodi CC, Coulibaly N, Sangare IS. La gangrène périnéale: A propos de 78 observations. [Article in French]. Afr J Urol 2006;12:44-50.

12. Korkut M, Içöz G, Dayangaç M, et al. Outcome analysis in patients with Fournier's gangrene: Report of 45 cases. Dis Colon Rectum 2003 May;46(5):64952.

13. Gürdal M, Yücebas E, Tekin A, Beysel M, Aslan R, Sengör F. Predisposing factors and treatment outcome in Fournier's gangrene. Analysis of 28 cases. Urol Int 2003;70(4):286-90.

14. Karian LS, Chung SY, Lee ES. Reconstruction of defects after Fournier gangrene: A systematic review. Eplasty 2015 May 26;15:e18.

15. Ozturk E, Sonmez Y, Yilmazlar T. What are the indications for a stoma in Fournier's gangrene? Colorectal Dis 2011 Sep;13(9):1044-7.

$* * * * * * * * *$

\section{Acknowledgements}

The authors acknowledge the technical support received from Dr kongni Gervais and Dr Carlson abomatei.

\section{Author Contributions}

Marvin Richie Dongmo Tsopmene - Substantial contributions to conception and design, Analysis and interpretation of data, Revising it critically for important intellectual content, Final approval of the version to be published

David Ngaroua - Substantial contributions to conception and design, Revising it critically for important intellectual content, Final approval of the version to be published Joseph Eloundou Ngah - Substantial contributions to conception and design, Revising it critically for important intellectual content, Final approval of the version to be published

Ignagali Ousmaila Bianpambe - Acquisition of data, Drafting the article, Revising it critically for important intellectual content, Final approval of the version to be published

\section{Guarantor of Submission}

The corresponding author is the guarantor of submission.

\section{Source of Support}

None

\section{Consent Statement}

Written informed consent was obtained from the patient for publication of this case report.

\section{Conflict of Interest}

Authors declare no conflict of interest. 


\section{Copyright}

(C) 2018 Marvin Richie Dongmo Tsopmene et al. This article is distributed under the terms of Creative Commons Attribution License which permits unrestricted use, distribution and reproduction in any medium provided the original author(s) and original publisher are properly credited. Please see the copyright policy on the journal website for more information.
Access full text article on other devices

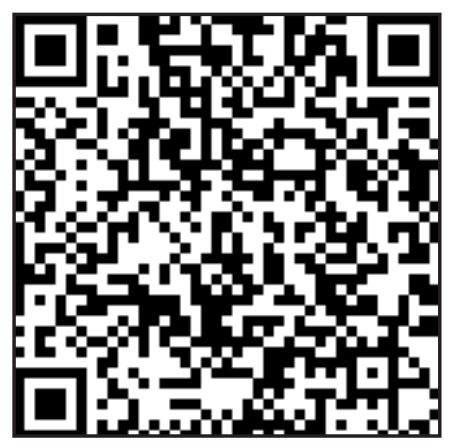

Access PDF of article on other devices

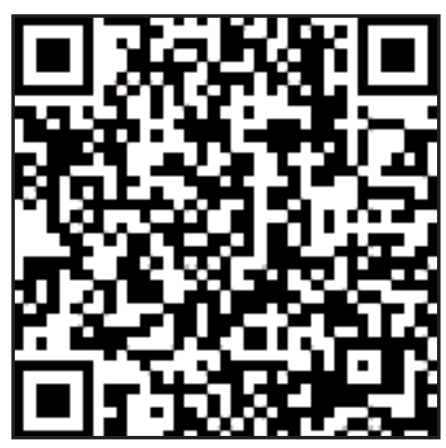

